\title{
Analysis of the Commercial Integration Between Agricultural and Agri-food Industries Sectors in Côte d'Ivoire
}

\author{
Noufou Coulibaly ${ }^{1, *}$, Kone Siaka ${ }^{1}$, Yapi Yapo Magloire ${ }^{2}$, Kouassi Yao Daniel Mardochée ${ }^{3}$ \\ ${ }^{1}$ Management and Applied Economics Department, National Polytechnic Institute Houphouët Boigny, Yamoussoukro, Côte d'Ivoire \\ ${ }^{2}$ Agriculture and Animal Science Department, National Polytechnic Institute Houphouët Boigny, Yamoussoukro, Côte d'Ivoire \\ ${ }^{3}$ School of Agronomy, Agroeconomy Section, National Polytechnic Institute Houphouët Boigny, Yamoussoukro, Côte d'Ivoire
}

Email address:

noufou_coulibaly@yahoo.fr (N. Coulibaly)

${ }^{*}$ Corresponding author

\section{To cite this article:}

Noufou Coulibaly, Kone Siaka, Yapi Yapo Magloire, Kouassi Yao Daniel Mardochée. Analysis of the Commercial Integration Between Agricultural and Agri-food Industries Sectors in Côte d'Ivoire. International Journal of Agricultural Economics.

Vol. 4, No. 4, 2019, pp. 144-153. doi: 10.11648/j.ijae.20190404.12

Received: April 8, 2019; Accepted: May 28, 2019; Published: June 13, 2019

\begin{abstract}
According to economic theory, when branches of the agricultural sector and of Agri-Food Industries (AFIs) are strongly integrated, this has the advantage of increasing ripple effect, thereby positively impacting the development of the agricultural sector. Our goal, was to appreciate the degree of integration of the agriculture and AFIs sectors in Côte d'Ivoire. We used the Leontief model as methodology, with the Ivorian economy's 2013 Supply-Use Table data. This study shows that: The amount of agricultural product, sold to AFIs is estimated at $22.82 \%$ of agricultural gross production (AGDP), which represents $38.13 \%$ of AFI's intermediate consumption; while the AFIs to Agriculture sales represent only $2.79 \%$ of the Agriculture branch's consumption. This reflects the fact that, the branches of the agricultural sector and of AFIs are poorly integrated. In addition, the weak relationship between them is unilateral in an Agriculture to AFI direction. Any innovation in any of the branches of this $\mathrm{AFC}$ will have minor effect on the mutation of the other branches. The weak integration between agriculture and agro-food industry is due to incoherent policies in Côte d'Ivoire, where, for a long time, processing of food agriculture has not been a big concern despite significant post-harvest losses in the sector, and due also to the inappropriate conditions for the emergence of an endogenous industrial fabric. In the light of our results, we made the following suggestions. The Government should develop policies that are consistent with each other, and work towards a healthy business climate. We also suggest encouraging and attracting donors to develop Agri-Food Industry, entrepreneurship and agribusiness. The Government should stimulate and promote a sound integration of training and research institutions with the business world. The Government will need to work towards a technical and financial support program for SMEs. Finally, we suggest the development of research on imported or local products.
\end{abstract}

Keywords: Agri-food Industry, Industry Dependence, Branch Integration Level, Value-Added Branch, Intermediate-Consumption Branch, End-Use Branches, Ripple Effect

\section{Introduction}

According to the FAO and UNIDO the development of Agri-Food Industries (AFIs) is a best palliative to sustainable development of agricultural sector [1-3]. They are likely to promote agricultural growth. Through the development of food industries and agribusiness, access to markets, financing and technical assistance can be facilitated for smallholder farmers, thereby effectively involving them in modern value chains. AFIs also help achieve food security.

In support of this assertion, Rastion and Ghersi [4], and Noufou [5], argue that the degree of integration (DI) of a branch measures the intensity of the links that a branch maintains with other branches of an economy and with final demand. A branch is all the more integrated into the other 
branches as its production is sold as intermediate consumption (processed product). It is all the less integrated as the production is intended for final consumption and therefore less processed. The high degree of integration of a branch is also synonymous with heavy reliance on the purchasing branches. Indeed, the more the branches of the economy are integrated, the more they can induce changes to others, if any of them internalizes a technological innovation. Hence they are considered as driving branches. The higher the degree of integration of branches of an economy into the agricultural sector, the more this fosters sustainable agricultural development, hence the development of the country. As a matter of fact, when the branches of the agricultural sector and those of AFIs are strongly integrated, any innovation in a branch benefits the others. This has the advantage of increasing the ripple effects, thereby positively impacting the development of the agricultural sector.

Despite the Government's investment efforts since 1960, the agricultural sector still faces difficulties, which are: low agricultural yield (10 to $30 \%$ of agricultural potential), low modernization of farms $(3 \%), 60 \%$ of poor's are in rural areas etc.

The analysis of the integration of branches or sectors (production, processing, and marketing) in an economy is grasped through the analysis of the structure of the branches of the economy as well as their interrelationship. This is why, as part of agricultural development measures, analyses are carried out over the entire Agri-Food Complex (AFC), which includes agriculture and agri-food industry (AFI); and a special focus is on AFIs that use agricultural raw materials as intermediate inputs to manufacture food.

In view of the above advantages, it can be argued that AFIs can play a leading role in agricultural development and poverty reduction in Africa and especially in Côte d'Ivoire. This is why we can ask ourselves: What were the failures behind the AFI sector not leading the Ivorian agricultural sector towards harmonious or sustainable development? Are the branches of the Ivorian economy well integrated with each other? And, is the agricultural sector well integrated with AFIs? In response to these concerns, we found it appropriate to analyse the intersectoral relations of the Ivorian economy, especially the AFC, in order to understand the structure of relationships among the branches of the economy, with a view to identifying the failures of sustainable development in the agricultural and agri-food industries.

The purpose of this study was to analyse the interrelationship between agricultural and Agri-Food Industries sectors in Côte d'Ivoire. Specifically, this involves: Estimating the degree of integration (DI) of agricultural branches with the agri-food industries.

\section{Literature Review}

This section discusses some studies of tools and practices for analysing the interrelationship between agricultural and Agri-Food Industries sectors in Côte d'Ivoire

Rastion and Ghersi in their studies on the global food system: "Concepts et méthodes, analyses et dynamique" applied to the 2005 Supply \& Use Table (SUT) or InputOutput Table (IOT) of France, the calculation of horizontal and vertical coefficients. These are indicators that characterize the Agri-food complex. The study shows that agriculture, historically a high value-added sector, is seeing its structural coefficient rise and become closer to all other sectors as it modernizes. This is justified by the different industrial strategies implemented [4].

As for Koko in his study on "The role of agri-food industries in agricultural growth: Case of Côte d'Ivoire", raised the question to know what was the impact of agri-food industries on agricultural growth in Côte d'Ivoire. The descriptive study, based on the 2008 Supply \& Use Table, allowed him to analyse the horizontal coefficients, the vertical coefficients and the degrees of integration of the various branches of AFIs. With these indicators, it was possible to assert that agri-food industry and agriculture were poorly integrated, given the $17 \%$ of agricultural production entering the AFIs processing process. In other words, his study showed that with this structure, AFIs were not determinants of agricultural production and growth. In addition, He noted that $93.96 \%$ of the value added of the entire agri-food production complex originated from agriculture, and that the consumption of raw agricultural products accounted for $58.34 \%$ of household food consumption compared to $41.3 \%$ for products processed by AFIs [6].

The definition of these indicators and their calculation methods provide the necessary information to develop the Input \& Output Table (IOT), the Overall Economic Table (OET) and the Social Accounting Matrix (SAM), which are major economic analysis instruments. Wassily Wassilyovich Leontief [7], is the forerunner of the input-output table, commonly referred to as SUT. It was at Harvard University, then a professor, that Leontief invented this table which is a synthesis of the exhaustive representation of François Quesnay's economic flows, of Keynes' demand logic and of Leon Walras's hypothesis on general equilibrium of the economic system, forming the theoretical basis for the model [8]. The study of interrelationships among the different branches of the economy underpinned by this table began in the early 1930s leading to two articles published in 1936 and 1937 in The Review of Economics Statistics and both included in his 1941 book entitled Structure of the American Economy, 1919-1929. In his first article of 1936, Leontief presented the SUT not only as an extension of François Quesnay's Economic Table, but also as a descriptive and statistical analysis tool providing "an empirical background to the study of the interdependencies among the different parts of a national economy, based on the theory of general economic equilibrium" [7-8]. In his second article of 1937, he better outlined the theoretical basis of the SUT with strong hypotheses linking intermediate and final productions of goods and services. Also, the advent of computing in the 1950s improved the development of the SUT and promoted its use as a model of economic analysis [9]. It is therefore a 
valuable framework for the analysis of trade flows between Agri-Food Industries and Agriculture.

The IOT or SUT analysis is based on a linear equation system showing the distribution of a branch's production across the economy [10]. The SUT is a dual entry table that tracks all economic transactions in goods and services. It helps describe the structure of the national economy and product flows, which makes it useful for prioritizing operations and highlighting the driving branches and the driven branches of the economy. It is considered, not only as a predictive medium to predict the effect of a given policy on the production of branches, but also as an economic impact analysis tool, because it helps measure the effects of the variation of an element of final demand for a strategic product on the entire economy [10-11].

\section{Methodology}

\subsection{Method}

To meet its objectives, this study is conducted following the below step process:

a) Assessment of branches integration's degree. This will involve assessing the degree of relationship among the various branches of the economy. As a matter of fact, the more the branches are integrated, the better the economy can be driven by a changing branch.

b) Focus on Agri-Food Complex to assess the integrated level between Agri-Food Industries and Agriculture.

\subsection{Model of Estimating "Degree of Integration"}

The Input-Output Table (IOT) or Supply-Use Table (SUT) invented by Wassily Wassilyovich Leontief [9] is the ideal tool for analysing "Degree of Integration" of economics sectors, specifically, Agri-Food Industries and Agricultural sectors. To meet the objectives of the study, two types of models or indicators will be estimated: Vertical coefficients (calculated from the Supply matrix) and Horizontal coefficients (calculated from the Use matrix). The SUT is summarised by figure 1 :

\begin{tabular}{|c|c|c|}
\cline { 2 - 3 } \multicolumn{1}{c|}{} & Branch Production Matrix & \multicolumn{1}{c}{ Final Use Table } \\
\hline Supply Table & Intermediate Consumption Matrix & \multicolumn{1}{|c}{} \\
\cline { 2 - 3 } & Table of Primary Distribution of Value Added (Va) &
\end{tabular}

Figure 1. Simplified representation of an SUT.

The tools (indicators) or models used to assess the degree of integration of sectors, are as follows:

According to Malassis and Ghersi "The degree of integration (DI) of a branch measures the intensity of the links that a branch maintains with the other branches and with final demand [12]. A branch is even more integrated in the other branches since its production is sold as intermediate consumption. It is even less integrated since its production is intended for final consumption ". The high degree of integration of a branch is also synonymous with high dependence on the purchasing branches. The degree of integration is determined with or without intra-consumption according to the following formula:

$$
\mathrm{DI}=\frac{\mathrm{IU}}{\mathrm{IU}+\mathrm{FC}}
$$

Where: DI: Degree of integration of branches,

IU: Intermediate Use,

FC: Final Consumption.

The degree of integration with intra-consumption is calculated by including the self-consumption of the branch considered in the intermediate uses (IU), unlike the calculation of the degree of integration without intraconsumption which excludes the self-consumption in intermediate uses (IU) of the branch.

To better quantify exchanges between agriculture and Agri-food industries, an Input-Output Table (IOT) was made using the 2013 SUT data, according to the model presented in table 1:
Table 1. IOT for Agriculture-AFIs.

\begin{tabular}{lll}
\hline & Agriculture (A) & $\begin{array}{l}\text { Agri-Food } \\
\text { Industries (AFIs) }\end{array}$ \\
\hline Agriculture (A) & $\mathrm{X}_{1.1}$ & $\mathrm{X}_{1.2}$ \\
Agri-Food Industries (AFIs) & $\mathrm{X}_{2.1}$ & $\mathrm{X}_{2.2}$ \\
Intermediate Consumption (IC) & $\mathrm{X}_{3.1}$ & $\mathrm{X}_{3.2}$ \\
Branch Production (BP) & $\mathrm{X}_{4.1}$ & $\mathrm{X}_{4.2}$ \\
\hline
\end{tabular}

With $\mathrm{X}_{1.1}$ : Agriculture to Agriculture Sale

$\mathrm{X}_{1.2}$ : Agri-food industries to Agriculture Sale

$\mathrm{X}_{2.1}$ : Agriculture to Agri-food Industries Sale

$\mathrm{X}_{2.2}$ : Agri-food industries to Agri-food industries Sale

$\mathrm{X}_{3.1}$ : Total intermediate consumption for agriculture

$\mathrm{X}_{3.2}$ : Total intermediate consumption for agri-food industries

$\mathrm{X}_{4.1}$ : Total production for Agriculture branch

$\mathrm{X}_{4.2}$ : Total production for Agri-food industries

The intensity of these flows is measured using 4 coefficients which are ratios between a branch's sales to, successively, its total intermediate uses, its production, its total purchases and to the purchasing branch's production. From this SUT, 4 coefficients will be estimated to assess the intensity of flows between the agricultural sector and AFIs. In other words, we will calculate the share of agricultural production that is processed by agri-food industries and the share of agricultural sales in the total intermediate consumption by AFIs and vice versa.

\subsection{Study Data}

The data used in this study are exclusively secondary data, mainly from the Directorate of Public Accounting, an entity 
of the Directorate General of Statistics, Ministry of Planning, Côte d'Ivoire. Specifically, data from the 2013 Supply-Use Table (SUT), which is the most recent, were used. Results are presented in the sections below. This SUT includes 44 branches aggregated into 21 branches for this study. This is because the branches of the sectors to be studied (agricultural and AFI) have not been aggregated in order to better analyse them, unlike those of the other sectors. The branches of the economy are therefore the following:

Table 2. Ivorian economy aggregated into 21 branches.

\begin{tabular}{|c|c|c|}
\hline & Aggregated Branches & Individual Branches \\
\hline 1 & Subsistence Agriculture (SA) & Subsistence Agriculture \\
\hline 2 & Industrial or Export-Oriented Agriculture (IEOA) & Industrial or Export-Oriented Agriculture \\
\hline 3 & Breeding and Hunting $(\mathrm{BH})$ & Breeding and Hunting \\
\hline 4 & Fishing and Fish Farming (FFF) & Fishing and Fish Farming \\
\hline 5 & Animal and Fish Production (AFP) & Animal and Fish Production \\
\hline 6 & Grain Processing and Manufacture of Starch Products (GPMSP) & Grain Processing and Manufacture of Starch Products \\
\hline 7 & Cocoa and Coffee Processing (CCP) & Cocoa and Coffee Processing \\
\hline 8 & Oilseed Industry (OI) & Oilseed Industry \\
\hline 9 & Bakery, Pastry, and Pasta (BPP) & Bakery, Pastry, and Pasta \\
\hline 10 & Dairy Industry and Fruit and Vegetable Industry (DIFVI) & Dairy Industry and Fruit and Vegetable Industry \\
\hline 11 & Beverage Industry (BI) & Beverage Industry \\
\hline 12 & Tobacco Industry (TI) & $\begin{array}{l}\text { Tobacco Industry } \\
\text { Forestry products }\end{array}$ \\
\hline 13 & Wood Industry (WI) & $\begin{array}{l}\text { Woodwork products and wood items } \\
\text { Paper and cardboard, edited and printed products } \\
\text { Products from oil processing \& coking }\end{array}$ \\
\hline 14 & Chemical Industry (CI) & $\begin{array}{l}\text { Chemicals } \\
\text { Rubber and plastic products }\end{array}$ \\
\hline 15 & Construction and Public Works (CPW) & $\begin{array}{l}\text { Construction works } \\
\text { Property services }\end{array}$ \\
\hline 16 & Energy and Water (EW) & Electricity, gas, water and ice cream \\
\hline 17 & Miscellaneous Industries (MI) & $\begin{array}{l}\text { Products from textile and clothing industry } \\
\text { leather and shoes, } \\
\text { Furniture, products from various industries }\end{array}$ \\
\hline 18 & Oil Extraction/Mining and Refining Industry (OEMRI) & $\begin{array}{l}\text { Products from extractive industries } \\
\text { Other metal and non-metal mineral products }\end{array}$ \\
\hline & & $\begin{array}{l}\text { Security and public administration services } \\
\text { Education }\end{array}$ \\
\hline 19 & Public Services (PuS) & $\begin{array}{l}\text { Health and social services } \\
\text { Personal and collective social services } \\
\text { Territorial correction }\end{array}$ \\
\hline 20 & Private Services (PrS) & $\begin{array}{l}\text { Hotel and restaurant services } \\
\text { Transportation and communication } \\
\text { Postal and telecommunications services } \\
\text { Financial services } \\
\text { Corporate services } \\
\text { Production of banking services }\end{array}$ \\
\hline 21 & Other Sectors (OSs) & $\begin{array}{l}\text { Base metal products and metal works } \\
\text { Machinery, electrical devices and equipment } \\
\text { Audio-visual and communication equipment and devices } \\
\text { Repairs (Maintenance) } \\
\text { Transportation equipment } \\
\text { Wholesale and retail }\end{array}$ \\
\hline
\end{tabular}

\section{Results and Discussions}

\subsection{Degree of Integration of Branches Analysis}

To assess the interrelation of the branches of the Ivorian economy, the degree of integration coefficients (DI) have been estimated, as illustrated by Equation 6 . The data are compiled in Table 3. Indeed, the more the branches are integrated among themselves, the better the economy can be driven by changes in branches. According to Table 3, the $\mathrm{AFC}$ as a whole (Agriculture and AFI), with integration coefficients of $47.24 \%$ with intra-consumption, and $43.66 \%$ without intra-consumption, is little integrated with other branches of the Ivorian economy.

There is also a low degree of integration $(6.38 \%$ without intra-consumption) between AFIs and the rest of the economy. The same is true for the agricultural sector. This is because products from the agricultural and AFI branches are mainly final consumption oriented and therefore little used as intermediate consumption or raw materials. This situation is similar in most developing countries, while in developed countries, the degree of integration of agriculture and AFIs into the economy is higher, as these sectors contribute 
significantly to the economy's raw material supply [6-7].

Table 3. Degree of integration of branches.

\begin{tabular}{lll}
\hline & $\begin{array}{l}\text { IU/ (IU+FC) with } \\
\text { intra-consumption }\end{array}$ & $\begin{array}{l}\text { IU/ (IU+FC) without } \\
\text { intra-consumption }\end{array}$ \\
\hline SA & $18.94 \%$ & $10.26 \%$ \\
IEOA & $76.10 \%$ & $74.37 \%$ \\
BH & $25.77 \%$ & $21.86 \%$ \\
FFF & $68.15 \%$ & $68.15 \%$ \\
AFP & $8.65 \%$ & $0.88 \%$ \\
GPMSP & $25.28 \%$ & $25.28 \%$ \\
CCP & $51.58 \%$ & $0.68 \%$ \\
OI & $55.76 \%$ & $9.71 \%$ \\
BPP & $0.51 \%$ & $0.51 \%$ \\
DIFVI & $18.15 \%$ & $8.91 \%$ \\
BI & $17.07 \%$ & $5.11 \%$ \\
TI & $0.00 \%$ & $0.00 \%$ \\
WI & $52.31 \%$ & $33.09 \%$ \\
CI & $62.09 \%$ & $44.13 \%$ \\
CPW & $37.61 \%$ & $36.25 \%$ \\
EW & $73.56 \%$ & $53.77 \%$ \\
MI & $53.38 \%$ & $46.51 \%$ \\
OEMRI & $97.84 \%$ & $93.01 \%$ \\
PuS & $0.03 \%$ & $0.00 \%$ \\
PrS & $57.72 \%$ & $39.93 \%$ \\
AB & $72.29 \%$ & $53.69 \%$ \\
Total Agriculture & $47.52 \%$ & $42.31 \%$ \\
Total AFI & $22.13 \%$ & $6.38 \%$ \\
Total AFC & $47.24 \%$ & $43.66 \%$ \\
Total Economy & $41.56 \%$ & $29.81 \%$ \\
\hline & & \\
\hline
\end{tabular}

Source: calculations made based on SUT 2013 at current prices [16]

Key: Subsistence Agriculture (SA), Industrial or Export-Oriented Agriculture (IEOA), Breeding and Hunting (BH), Fishing and Fish Farming (FFF), Animal and Fish Production (AFP), Grain Processing and Manufacture of Starch Products (GPMSP), Cocoa and Coffee Processing (CCP), Oilseed Industry (OI), Bakery, Pastry and Pasta (BPP), Dairy Industry and Fruit and Vegetable Industry (DIFVI), Beverage Industry (BI), Tobacco Industry (TI), Wood Industry (WI), Chemical Industry (CI), Construction and Public Works (CPW), Energy and Water (EW), Miscellaneous Industries (MI), Oil Extraction/Mining and Refining Industries (OEMRI), Public Services (PuS), Private Services (PrS), Other Branches (OB), Agri-Food Industry (AFI), Agri-Food Production Complex (AFPC), Intermediate Use (IU), Final Consumption (FC)

However, high degrees of integration can be noticed for products of branches such as Industrial and Export-Oriented Agriculture (about $76 \%$ with intra-consumption, and about $74 \%$ without intra-consumption) and fish \& fish farming (about $68 \%$ with and without intra-consumption). Regarding Industrial and Export-Oriented Agriculture, it should be stressed that the high rate is due to the hard currency they generate for the country.

The oilseed and cocoa \& coffee processing industries have relatively high degrees of integration respectively at $55.76 \%$ and $51.58 \%$ with intra-consumption. However, their degrees of integration without intra-consumption are very low (about $10 \%$ and $0.68 \%$ ). This type of integration does not benefit the other branches, because most of the products of these branches are self-consumed by the branch itself. For further analysis on the level of AFC integration, we also studied intra-complex dependence through a two-sector SUT - Agriculture and AFIs.

The analysis focused on internal exchanges in the complex (Agriculture and Agri-food Industries) and sales and purchasing flows between Agriculture and Agri-food industry (see Table 4).
Table 4. Internal exchanges in AFC (millions of CFA francs).

\begin{tabular}{lll}
\hline & Agriculture (A) & $\begin{array}{l}\text { Agri-Food } \\
\text { Industry (AFIs) }\end{array}$ \\
\hline Agriculture (A) & 222945 & 896285 \\
Agri-food industries (AFIs) & 25278 & 812124 \\
Intermediate consumption (IC) & 906246 & 2350401 \\
Production by the branch (PB) & 3927040 & 3456579 \\
\hline
\end{tabular}

Source: calculations based on 2013 SUT at current prices [16].

It clearly appears from Table 4 a marked inequality between the exchanges of the branches making up the AFC. Indeed, AFI branches allocate 896.285 billion CFA francs to the purchase of agricultural products, while agriculture branches spend only 25.278 billion CFA francs on purchases of AFI products. The data in Table 4 helped us estimate the coefficients of exchanges between the agricultural and agrifood sectors. These data are compiled in Tables 5 and 6 .

Table 5. Coefficients of Exchanges between Agriculture and Agri-Food Industry.

\begin{tabular}{ll}
\hline & Sales from Agriculture to AFIs VA=896285 \\
\hline VA/AIU & $70.17 \%$ \\
VA/AGP & $22.82 \%$ \\
VA/AFIIC & $38.13 \%$ \\
VA/AFIGP & $25.93 \%$ \\
\hline
\end{tabular}

Source: calculations based on 2013 SUT at current prices [11]

Key: Agriculture $=$ Subsistence Agriculture (SA) + Industrial and ExportOriented Agriculture (IEOA) + Breeding and Hunting (BH), Sales from Agriculture to Agri-Food Industry (SAAFI), Agriculture Intermediate Use (AIU), Agriculture Gross Production (AGP), Agri-Food Industries Intermediate Consumption (AFIIC), Agri-Food Industries Gross Production (AFIGP).

Table 6. Coefficients of exchanges between Agri-food Industry and Agriculture.

\begin{tabular}{ll}
\hline & Sales from AFIs to Agriculture VIAA=25278 \\
\hline SAFIA/AFIIU & $2.84 \%$ \\
SAFIA/AFIGP & $0.73 \%$ \\
SAFIA/AIC & $2.79 \%$ \\
SAFIA/AGP & $0.64 \%$ \\
\hline
\end{tabular}

Source: calculations based on 2013 SUT at current prices [16].

Key: Agriculture $=$ Subsistence Agriculture (SA) + Industrial and ExportOriented Agriculture (IEOA) + Breeding and Hunting (BH), Sales from Agri-Food Industries to Agriculture (SAFIA), Agri-Food Industries Intermediate Use (AFIIU), Agriculture Gross Production (AGP), Agriculture Intermediate Consumption (AIC), Agri-Food Industries Gross Production (AFIGP).

The intensity of the flows is measured with 4 coefficients which are a branch's sales ratios to successively its total intermediate uses, its production, its total purchases and to the purchasing branch's production (See Tables 5 and 6). The unequal exchange between agriculture and agri-food industry, discussed in the section above, is better seen in the tables above, where the calculated coefficients show that Agriculture to AFI sales represent $38.13 \%$ of AFIs intermediate consumption (Table 5) while AFIs to Agriculture sales only represent $2.79 \%$ of the Agriculture branch's consumption (Table 6).

These results show once again, the low interdependence 
between agricultural branches and AFI branches: According to these results, it could also be argued that relationships between agriculture and AFIs are almost unilateral. It is true that agricultural product sales to AFIs account for $70.17 \%$ of agriculture intermediate sales; however, these account for only $22.82 \%$ of the production by agricultural branches, $37.56 \%$ of intermediate consumption and $25.6 \%$ of the production by AFI branches. AFI sales to agricultural branches are very low, and the corresponding coefficients are virtually insignificant $(0.64 \%)$. This is because only the Breeding and Hunting branch from agricultural branches buys food processed by AFIs to feed animals.

In summary, it can be argued that the branches of the agricultural sector and of AFIs are poorly integrated. In addition, the weak relationship between them is unilateral in an Agriculture to AFI direction. Therefore, any innovation in any of the branches of this AFC will have minor effect on the mutation of the other branches. It could be argued that the branches are slightly interdependent and therefore slightly dynamic. As confirmed by Koko's study, it can be argued that Ivorian AFIs are not determinants of agricultural production and growth [6].

Based on the economic principle that the agricultural industry is a palliative for agricultural sector sustainable development, how can we explain this weak integration between the two sectors, for a country like Côte d'Ivoire, whose agriculture is the engine of its economy growth? This concern can be explained by the lack of a national strategy focused on the conservation and processing of food products, on the one hand, and the non-emergence of a dynamic and endogenous industrial fabric on the other hand.

Indeed, since independence, Côte d'Ivoire chose to develop its export crops (and in the forefront, coffee and cocoa, cotton, palm, rubber, cashew) for currency issues to the detriment of food crops by importing very cheap cereals (rice, wheat) from world markets because of depressed prices. It was also in that spirit that the policy of industrialization, based on cash crop processing, was directed in order to further increase incomes [13-15].

There was certainly a rationale behind this deliberate policy: to supply townspeople at low cost and thereby ensure social peace in the city; provide income through taxes levied on such commodities upon import. However, this choice has led to a massive increase in cereal imports and strong reliance on foreign markets, the catastrophic effects of which have been felt after world food prices increased.

Unfortunately, since independence, Côte d'Ivoire has experienced a population explosion that has multiplied its population by six. From 3,000,000 people at the beginning of independence, the population increased in 1980 to 5,000,000 and in 2009 to $20,617,068$ with an average annual growth rate of $3.8 \%$. This has been compounded by rural exodus since 1950 . In addition, with a longer life expectancy $(55.45$ years in 2009 against 42 years in 1962), the elderly, rendered inactive because of arduous work in the countryside, are still more numerous and also remain dependent longer. At the same time, it should also be noted that with declining infant mortality and lack of significant change in the birth rate, the number of young children is increasing. Finally, with an educated rate of $62 \%$, many young people are excluded from agricultural work. Therefore, rural balances are logically challenged. This has resulted in increased demand for food products borne by farmers [16]. However, there has been a decline in productivity given the long fallow periods that can no longer be observed and yet essential for soil reconstitution in the absence of improved agricultural techniques. The food security issue is therefore acute.

The government, aware of these serious dysfunctions, decided to revive food crops (roots, tubers, cereals, vegetables, fruits and livestock) with a set of programs for food security. Today, food crops are of paramount importance to people and livestock. Produced by rural populations, they are intended for self-consumption, even if a relatively large quantity is marketed. They cover $2,448,000$ ha, producing $18,000,000$ tonnes per year, contribute $14.7 \%$ of the value of GDP, and employ more than 2,500,000 agricultural workers, or about $85 \%$ of the active agricultural population, mostly women. It should be noted that in addition to the production of plant resources, the food chain is based on the production of animal and fish resources. The growth in production of animal and fish resources by volume, according to the Strategic Support Program for Scientific Research (PASRES), was around 6\% in 2016 compared to $3 \%$ in 2011 , a performance that should still be improved in order to achieve food self-sufficiency. Post-harvest losses are significant and range from 35 to $70 \%$. In recent years, food crops have become real cash crops and some of these products are increasingly exported to the sub-region (Mali, Burkina, Liberia, Niger etc.). They can be grouped into five (05) large families as below [17-19]:

Table 7. List of food crops grown in Côte d'Ivoire.

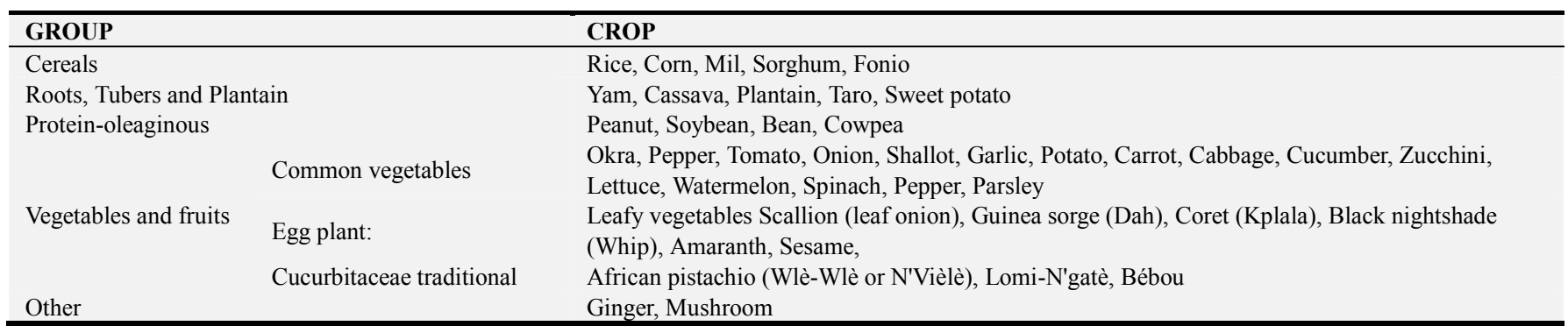

The weak integration between the agricultural sector and the agribusiness sector, illustrated in our findings, is the 
result of inconsistent policies carried out in Côte d'Ivoire since independence.

Local processing occurs at three different levels: artisanal, semi-industrial and industrial. Artisanal processing mainly concerns food products, in this case consumer goods such as starch, cereals and vegetables. Overall, the processing rate remains very low, with the exception of rice, where almost all paddy rice produced is processed into milled rice by small units. And, the technologies and processes used are rather rudimentary. There is also a lack of funding.

Semi-industrial processing is on the one hand, supported by the National Centre for Agronomic Research (CNRA), whose research activities aim to increase the production and productivity of the agricultural sector and the agri-food industry. This Center holds the methods for processing cassava and plantain into pre-cooked flour, and yam into flour "Bonfoutou" in the field of food processing. On the other hand, the CDT (Centre for Demonstration and Promotion of Technologies), which was created in 2009, has technologies for the processing, conservation (cold rooms) and packaging of various agricultural products, including food products, fruits and vegetables. Promotion and accessibility for local investors remain difficult.

Industrial processing is essentially done by multinational firms (Nestlé, Cemoi, Blohorn etc.). They alone process over $80 \%$ of the agricultural raw materials processed in Côte d'Ivoire. The remaining $20 \%$ is processed by small and medium-sized enterprises (SMEs), from which agricultural producers are absent. Operations by the various operators in the sector, made it possible to obtain the following result:

a) 1st-stage processing: Results are satisfactory with a rate approaching $100 \%$ for most commodities (oil palm, rubber, cotton, etc.) except for cocoa and cashew whose processing rates were $23 \%$ and less than $3 \%$ respectively before 2006 . With the investments made in both sectors, the rates rose to $35 \%$ for cocoa and $15 \%$ for cashew in 2012;

b) 2nd-stage processing: Results are still low, except for oil palm sector where nearly $80 \%$ of the crude oil produced is refined locally. The offee processing rate is around 20\%; the one for cocoa, cotton (cotton fibre) and rubber is less than $2 \%$;

c) 3rd-stage processing: mainly concerns oil palm with the production of margarines, cosmetics, etc. [3].

In fact, agricultural products in general are very little processed, especially subsidence agriculture where food crops have a high degree of perishability. Their degree of processing is mainly artisanal, and sometimes at the level of initial industrial processing. The reasons are: low degree of research in food crop processing, lack of investment to support industries. Industrialization. Rarely the processing of food crops reaches the second or third stage of processing, thanks to the investments of multinationals. The agricultural sector offers great opportunities for developing Agri-food industries because of the availability of raw materials and the growing demand for food due to rapid population growth $(2.2 \%$ / year).

\subsection{The Constraints to a Good Integration of Agriculture and Agri-food Industries Sectors}

We could therefore wonder why the strong growth of the local market during the first two decades of independence induced by the initial choices of the (liberalism, political stability, external openness, voluntarist growth) model as well as the abundant financial resources that the strategy entailed did not result in the building of a dense fabric of industries? So, did the Ivorian strategy present serious hazards in terms of skill transfer? A failure of this strategy may jeopardize continued industrial growth. Yet, this hazard is inherent in successful unbalanced growth through external openness.

Indeed, several constraints were behind this failed industrialization, and are grouped into three broad categories: first, those related to the nature of the industry; second, those related to the hostile administrative and political environment; and third, those related to the lack of industrial culture [20].

\subsubsection{Constraints Related to the Nature of Industry}

If few Ivorians (about 5\%) have created industrial firms, it is certainly not because of a lack of entrepreneurship, as private initiatives have emerged in the craft, trade and service sectors over the last decade. It is therefore reasonable to ask whether the specificities of the industrial sector are not responsible for the sector's low attractivity to local entrepreneurs, including:

a) The indivisibility of industrial investments, which is a barrier to entry in relation to real estate, trade, crafts, transportation or services. The industry is considered a capitalistic sector. The profitability for these capital investments is determined by the market size, which allows for economies of scale, and by the rate of utilization of production capacity, which usually requires a longer maturation period than other sectors to reach cruising level. In Côte d'Ivoire, the market for industrial products is limited by the size of the population and its low purchasing power. Large potential consumers of manufactured goods belong to advantaged social classes. The strong income growth generated by the success of the Ivorian model until the outbreak of the crisis encouraged the privileged strata to adopt the consumption model conveyed by expatriates, which explains their preference for imported industrial products over local products. For all these reasons, the import-substitution industry could only develop with strong protection barriers (tariffs, quotas and export licenses, tax exemptions by investment codes). Despite all the facilities granted to the industry by the Ivorian Government, the profits that this sector could expect remained very limited compared to those offered by competitive sectors. Therefore, how to convince the still very small number of Ivorian's with significant savings capacity to invest in the industry, knowing they will have to wait at least 4 to 5 years before having a chance to draw profit from their capital.

b) The higher technicality (competence, professionalism 
etc.) of the industry is another barrier to entry. In fact, the industry requires greater managerial capacities than other sectors. Organizational capacity, fostered by integration into national and international technical, financial and information networks, which facilitates the ability to forecast and plan technological changes and innovations, and is essential to competitiveness is also an entry barrier.

c) The business climate, which helps (or not, if bad) firms to emerge, is also an explanatory factor for the attraction of Foreign Direct Investments which can be a factor in the industrialization of the country.

\subsubsection{Constraints Related to Administrative and Political Environment}

a) The policy to make private capital and foreign firms Ivorian frightened investors, who had to change their nationalities to avoid tax pressure and a transfer of their firms and skills, and at the same time to benefit from funds originally intended to revive Ivorian SMEs, which is a circumvention of the legislation then in force

b) Lack of policy coherence. For example, the Government-endorsed import of rice inhibits an efficient revival of the local production capacity for this commodity, which is essential for food security and food sovereignty.

c) The cost of production factors such as petrol, electricity, water, credit or capital, and communication to a lesser extent, is today the most significant constraint to the development of SMEs [20-22]. For many promoters, the only concern for the Government is to bail out its coffers without worrying about the impact of tax burden on firms. In addition to these, there are shortcomings in the judicial system, which only increase banks' reluctance to participate in the financing of SMEs/SMIs. They complain that they have difficulties in recovering their debts and in enforcing guarantees. It takes, according to them, three to four years to have court permission to access the guarantees given. By then, the debtor has time to arrange their insolvency.

d) Administrative burden for setting up a business has significantly improved with the creation of CEPICI (Investment Promotion Centre). However, the conditions to settle, to import production factors, to export production, etc. are still difficult because of administrative and customs harassment (subjective cumbersome procedures). It is also observed that some nationals seem to have more difficulty than large foreign firms in obtaining licenses, especially when they do not belong to social groups linked to political leaders network

e) Poor governance also remains a major handicap to the emergence of a broad industry base which, even the single window strategies and the political will to talk about could not stem.

f) Lack of technical and economic information in the different sectors of the economy, a necessary ingredient at the time of the creation or during the operation of a firm also remains a handicap.

g) Also of note is the weak competence of government entities responsible for promoting firms in feasibility and market studies. While profit taxation is the main argument in favour of Côte d'Ivoire, it is clear that the tax burden on labour and consumption (especially the import of inputs) largely offsets this competitive advantage.

\subsubsection{Constraints Related to Lack of Industrial Culture}

Indeed, we believe that, the fragility of the African economic sphere is due to cultural logics (solidarity, mutual aid etc.) that are incompatible with the business world in the industrial sector [23]. These traditional behaviours create a community constraint of rights and obligations that largely determine individual economic calculation. Africa is thought to be a huge community transfer society, which partly explains the failure of macroeconomic models. Cultures and traditions do not respect the rules of the game of market economy, and induce strong family and social pressures, compromising the economic calculation, whereas this should ensure business balance through the professional virtues of rigor, sober management, sustained operation, and selffinancing. Individuality is only in relation to the group and for the group in the Ivorian culture. Rationality, rigor, diligence, and professionalism are not Ivorian entrepreneurs' strong points. According to our investigations, $65 \%$ of Ivorian firms suffer from poor management or governance, and $39 \%$ from poor business organization; about 33\% for financing reasons. $83 \%$ of Ivorian firms experience these failures, reflecting an overall problem of governance, mainly due to family and social pressure.

We agree with Chevassu Jean Marie's statement that, the low level of industrialization and the small number of Ivorian entrepreneurs are much more due to psycho-ethnological factors ("mentalities are not suited to industrial matters") than to large foreign firms accused of stifling any attempts to emerge, and to technical factors (lack of training, funding) [20].

\subsection{Determinants for the Emergence of an Efficient Industrial Fabric}

Based on the constraints to a powerful industrial fabric presented above, actions have been identified and are as follows:

a) The Government will need to develop policies that are consistent with each other; instil good governance for a healthy business climate, a prerequisite for attracting domestic and international investors.

b) The Government should stimulate and encourage a sound integration of training and research institutions with the business world in order to improve the professionalism of the country's future executives;

c) It will also need to identify and coach national investors' first, then international ones. This will have the benefit of forming a class of investors. 
d) The Government should develop an industrialization program, in which the following actions need to be taken:

$d_{1}$ ) The Government should encourage banking in order to build up funds in financing institutions (banks, microfinance institutions) by facilitating access to such institutions, like Orange Money outlets. This will have the advantage of building up capital and selling it at motivational rates for investors (maximum 5\%).

$\mathrm{d}_{2}$ ) Government entities responsible for promoting firms (Ministry of Industry, CEPICI, Chamber of Industry and Commerce, etc.) should direct investors to national or international research firms for feasibility and market studies.

$d_{3}$ ) Government entities responsible for promoting firms (Ministry of Industry, CEPICI, Chamber of Industry and Commerce, etc.) should direct investors to national or international research firms for feasibility and market studies.

$\mathrm{d}_{4}$ ) The Government should adopt outsourcing or fragmented production processes as an opportunity. Indeed, this globally advocated strategy distributes the production of the different material and immaterial (services) components across the planet depending on what the actors in different countries can offer. Outsourcing thus remains an opportunity for the Ivorian economy, in sub-regional value chains, in terms of extra-industrial production, to compensate for technological, and managerial and organizational capacity failures.

\section{Conclusion}

According to economic theory, when of Agri-Food Industries (AFIs), use agricultural products as intermediate inputs (Raw materials), their dynamics suggests that they address a high demand for goods from agriculture. This has the effect of increasing farmers' income, reducing rural poverty and promoting standardization and intensified agricultural production to meet both quantity and quality demands. Also, with the job creation they generate, AFIs help the agricultural sector to be decongested, by moving the surplus of agricultural labour towards them, in addition to adding value to agricultural products. So, considering their advantages, AFIs can play a leading role in agricultural development and poverty reduction in Africa and especially in Côte d'Ivoire. The purpose of this study was to assess the degree of commercial relationship between the agricultural and the agro-industry sectors. This study shows that the quantity of agricultural product, sold to AFIs is estimated at $22.82 \%$ of agricultural gross production (AGDP), which represents $38.13 \%$ of AFI's intermediate consumption, while AFIs to Agriculture sales represent only $2.79 \%$ of the Agriculture branch's consumption. This reflects that the branches of the agricultural sector and of AFIs are poorly integrated. In addition, the weak relationship between them is unilateral, in an Agriculture to AFIs direction. Any innovation in any of the branches of this AFC will have minor effect on the mutation of the other branches. It could be argued that the branches are slightly interdependent and therefore slightly dynamic. It can also be argued, that Ivorian
AFIs are not determinants of agricultural production and growth. This weak integration between agriculture and the agro-food industry is the result of incoherence of policies in Côte d'Ivoire, where, for a long time, processing of food agriculture has not been a big concern, despite the important post-harvest losses in this sector, in one hand; and in other hand, due also to the inappropriate conditions for the emergence of an endogenous industrial fabric.

In light of these results, it is therefore appropriate and necessary to adjust the AFIs to the potential of agricultural production with a view to a coherent agricultural policy. So, we propose the following suggestions. The Government should develop consistent policies and work towards a healthy business climate. The Government needs to work towards a technical and financial support program for SMEs. Therefore, we suggest the encouragement and attraction of donors to develop Agri-Food Industry, entrepreneurship and agribusiness. The Government should stimulate and promote a sound integration of training and research institutions with the business world. We suggest the development of research on imported or local products.

\section{References}

[1] FAO; ONUDI. (2010). Initiative pour le Développement de l'Agribusinesset des Agro- industries. Vienne \& Rome.

[2] FAO. (2012). The State of Food Insecurity in the World: Economic growth is necessary but not sufficient to accelerate reduction of hunger and malnutrition. Rome.

[3] Gérard De Bernis in Emmanuel Martin (2012), L'industrialisation, condition du développement de l'Afrique?

[4] Rastoin, J.-L., \& Ghersi, G. (2010). Le systèmealimentairemondial: Concepts et méthodes, analyses et dynamiques. Paris-Versailles, Éditions Quæ.

[5] Noufou, C. (1993). "Stratégie de développement de l'industrie agro-alimentaireen Côte d'Ivoire". Vol. No 30. Sérieconférence. Université Laval, Quebec-Canada.

[6] Koko, K. B. (2013). "Le rôle des Industries Agroalimentairesdans la croissanceagricole:Cas de la Côte d'Ivoire". U. I. Z. Mémoire:Doctoraten Sciences Economiques.

[7] Leontief, W. W. (1936). Quantitative input and output relations in the economic systems of the United States. Review of Economics and Statistics, vol. 18, n³, p. 105-125.

[8] Akhabbar, A., \& Lallement, J. (2011). « Appliquer la théorie économique de l'équilibre général»: de Walras à Leontief. Paris, GRESE.

[9] Yu, Y., Hubacek, K., Guan, D., \& Feng, K. (2010). Construction and application of Regional Input-Output Models: Assessing Water Consomption in South East and North East of England. Ecological Economics, vol 69, pp1140-1147.

[10] Zaoujal, N. (2012). Technique de plannification: Analyse Inpout-Output (modèle de Leontief). Rabat: Cours dispensé à l'Institut National de Statistiqueetd'Economie Appliquée (INSEA) de Rabat. 
[11] Institut National de Statistique de Côte d'Ivoire. (2016). Compte de la Nation 2013. Division Comptabilité Nationale: Département des Statistiques et Synthèses Economiques.

[12] Malassis, L., and Ghersi, G. (1992). "Initiation à l'économie agro-alimentaire". Paris: HatierAupelf.

[13] Céline Yolande KOFFIE-BIKPO et Axel Désiré Dabié NASSA (2011) «Evolution des politiques de commercialisation du Vivriers en Côte d'Ivoire», L'Harmattan, 5-7, rue de l'École-polytechnique; 75005 Paris p 1-15.

[14] Ministère de l'Industrie de Côte d'Ivoire (2014), Agence de Promotion des Exportations de Côte d'Ivoire, Projetd'Appui à la Revitalisation et à la gouvernance des PME "Etude sur la compétitivité des entreprises ivoiriennes" 106p.

[15] Ministère de l'industrie. (2012). "Nouvelle Politique Indistrielle de la république de Côte d'Ivoire."

[16] Ducroquet, H., Tillie, P., Louhichi, K. (2017), «L'agriculture de la Côte d'Ivoire à la loupe: Etat des lieux des filières de production végétales et animales et revue des politiques agricoles».
[17] Ministère de l'agriculture. (2012). "Stratégie de transformation des produits agricoles" Direction de la Valorisation des Produits, Côte d'Ivoire.

[18] Ministère de l'Agriculture (2013), "Stratégie Nationale de Dévelppement des Cultures Vivirières (SNDCV)", DGPSA, P. 167.

[19] Ministère de l'Agriculture et du development rural (2016). Annuaire des Statistiques Agricoles 2010, 2012, 2014, 2016.

[20] Chevassu J. M. (1997), Le modèle ivoirien et les obstacles à l'émergence de la petite et moyenne industrie (PMI), 18p.

[21] CIRES, Cellule d'Analyse de Politiques Economiques (2009) in IOS Partners (2014), Etude sur la Compétitivité des entreprises ivoiriennes, $p .16$.

[22] IOS Partners (2014), Etude sur la Compétitivité des entreprises ivoiriennes, $105 \mathrm{p}$.

[23] F.-R. Mahieu, Les Fondements de la crise écotiomique en Afrique, L'Harmattan, Coll. Logiques économiques B, Paris, 1990. 23. Op. cit., p. 321. 24. Cité par Y.-A. Fauré, op. cit., p. 318. 